\title{
Antiretroviral treatment use, co-morbidities and clinical outcomes among Aboriginal participants in the Australian HIV Observational Database (AHOD)
}

\author{
David J. Templeton ${ }^{1,2,3^{*}}$, Stephen T. Wright ${ }^{1}$, Hamish McManus ${ }^{1}$, Chris Lawrence ${ }^{4}$, Darren B. Russell ${ }^{5,6,7}$,
} Matthew G. Law ${ }^{1}$, Kathy Petoumenos ${ }^{1}$ and on behalf of the Australian HIV Observational Database

\begin{abstract}
Background: There are few data regarding clinical care and outcomes of Indigenous Australians living with HIV and it is unknown if these differ from non-Indigenous HIV-positive Australians.

Methods: AHOD commenced enrolment in 1999 and is a prospective cohort of HIV-positive participants attending HIV outpatient services throughout Australia, of which 20 (74 \%) sites report Indigenous status. Data were collected up until March 2013 and compared between Indigenous and non-Indigenous participants. Person-year methods were used to compare death rates, rates of loss to follow-up and rates of laboratory testing during follow-up between Indigenous and non-Indigenous participants. Factors associated with time to first combination antiretroviral therapy (CART) regimen change were assessed using Kaplan Meier and Cox Proportional hazards methods.
\end{abstract}

Results: Forty-two of 2197 (1.9\%) participants were Indigenous. Follow-up amongst Indigenous and non-Indigenous participants was $332 \& 16270$ person-years, respectively. HIV virological suppression was achieved in similar proportions of Indigenous and non-Indigenous participants 2 years after initiation of CART ( $81.0 \%$ vs $76.5 \%, p=0.635$ ). Indigenous status was not independently associated with shorter time to change from first- to second-line CART (aHR 0.95, $95 \% \mathrm{Cl}$ $0.51-1.76, p=0.957)$. Compared with non-Indigenous participants, Indigenous participants had significantly less frequent laboratory monitoring of CD4 count (rate:2.76 tests/year vs 2.97 tests/year, $p=0.025$ ) and HIV viral load (rate:2.53 tests/year vs 2.93 tests/year, $p<0.001$ ), while testing rates for lipids and blood glucose were almost half that of non-indigenous participants (rate:0.43/year vs 0.71 tests/year, $p<0.001$ ). Loss to follow-up ( $23.8 \%$ vs $29.8 \%, p=0.496)$ and death $(2.4 \%$ vs $7.1 \%, p=0.361)$ occurred in similar proportions of indigenous and non-Indigenous participants, respectively, although causes of death in both groups were mostly non-HIV-related.

Conclusions: As far as we are aware, these are the first data comparing clinical outcomes between Indigenous and non-Indigenous HIV-positive Australians. The forty-two Indigenous participants represent over $10 \%$ of all Indigenous Australians ever diagnosed with HIV. Although outcomes were not significantly different, Indigenous patients had lower rates of laboratory testing for HIV and lipid/glucose parameters. Given the elevated risk of cardiovascular disease in the general Indigenous community, the additional risk factor of HIV infection warrants further focus on modifiable risk factors to maximise life expectancy in this population.

Keywords: HIV, Cohort study, Indigenous, Australia

\footnotetext{
* Correspondence: david.templeton@sswahs.nsw.gov.au

'The Kirby Institute, UNSW Australia, Sydney, NSW 2052, Australia

${ }^{2}$ RPA Sexual Health, Sydney Local Health District, Camperdown, NSW 2050,

Australia

Full list of author information is available at the end of the article
} provide a link to the Creative Commons license, and indicate if changes were made. The Creative Commons Public Domain Dedication waiver (http://creativecommons.org/publicdomain/zero/1.0/) applies to the data made available in this article, unless otherwise stated. 


\section{Background}

The rate of HIV diagnoses among Australian Aboriginal and Torres Strait Islander (hereafter "Indigenous") people over the past decade has been similar to that among non-Indigenous Australians [1]. However, factors such as high rates of sexually transmitted infections, social disadvantage and poor access to health services may lead to an elevated risk of HIV infection [2], as has been witnessed among Canada's Indigenous population [3].

Australia's Indigenous people are a heterogenous group, and the diversity of language, socio-cultural, geographic and economic factors will impact on management of Indigenous individuals living with HIV [4]. Compliance with HIV therapy is recognised as a key factor in disease progression and prognosis [5], and although challenging in any setting, it is likely to be complicated by a number of these factors in Indigenous Australians [6]. Indigenous people have poorer overall health outcomes and poor access to health services [7] which is of specific concern among those living with HIV as failure to access HIV care is also an important risk factor for HIV disease progression [5]. Such issues, along with other co-morbidities in this population, have the potential to considerably lower survival rates in Indigenous HIV-infected individuals [6].

There are few published data regarding clinical outcomes and co-morbidities of Indigenous Australians living with HIV and it is unknown if these differ from non-Indigenous HIV-positive Australians. Our aim was to describe demographic factors, clinical characteristics, and co-morbidities among Indigenous participants, and compare them with those of non-Indigenous participants enrolled in a large Australian clinical cohort of HIV-positive patients.

\section{Methods}

The Australian HIV Observational Database (AHOD) was established in July 1999 . One of the primary objectives of AHOD is to monitor trends in combination antiretroviral therapy (cART) use and HIV disease outcomes among patients with HIV in Australia; areas in which data from Indigenous individuals are lacking. At the time of the present analysis, there were 27 AHOD sites around Australia including HIV tertiary referral centres, HIV specialist general practice clinics and sexual health clinics. Consecutive clinic patients were invited to participate in AHOD in a non-random manner, thus recruitment of Indigenous patients was coincidental. Key clinical data are transferred to the co-ordinating centre, the Kirby Institute, UNSW Australia, on a 6-monthly basis. These data include patient demographics, HIV disease stage, and antiretroviral treatment history. Participant deaths are reported by study sites to The Kirby Institute AHOD team. The deceased's attending physician enters their clinical data into a standardised coding of causes of death in HIV (CoDe) form [8] and the cause of death is then determined as being related to HIV or not. A detailed description of the AHOD cohort has previously been published [9].

\section{Study population}

Analyses were restricted to AHOD sites that report Indigenous status, recruited to AHOD by March 2013.

\section{Statistical methods}

Descriptive statistics were performed comparing key patient demographic and HIV related clinical information between Indigenous and non-Indigenous AHOD participants. Factors investigated include: basic demographic characteristics; HIV diagnostic characteristics: age at diagnosis, year of diagnosis, CD4 count at diagnosis \& risk exposure categories; comorbidities: Hepatitis B \& Hepatitis C serology results; antiretroviral treatment factors: CD4 count at commencement of cART, cART regimen prescribed, virological and immunological response to cART. Loss to follow-up (defined as not having returned to AHOD clinic in the last 12 months) and causes of death (AIDS versus non-AIDS related) were compared between Indigenous and non-Indigenous participants. Where relevant, statistical comparisons were made using chi-square tests for categorical variables, and independent $\mathrm{t}$-tests or non-parametric equivalent as appropriate, for continuous variables. Person year methods were used to compare death rates, rates of loss to follow-up and of laboratory testing during follow-up between Indigenous and non-Indigenous participants. Laboratory tests included blood glucose and lipids, as well as CD4 counts and HIV viral load tests.

Factors associated with time to first cART regimen change (defined as the addition of two or more drugs to the regimen, or at least one new cART class being used) were assessed as a proxy for adherence to, and tolerability of, the initial cART regimen prescribed using Kaplan Meier and Cox Proportional hazards methods as previously described in detail [10], with a priori inclusion of Indigenous status in the multivariate model. Off treatment periods were included in duration to time of change. Risk factors assessed are outlined in Table 2 and the footnote to Table 2. The model was determined using backward stepwise methods. Factors in univariate analyses with $p$-value $<0.1$ were assessed in the multivariate analysis. The final model contained factors with $p$-value $<0.05$.

Ethics approval for the AHOD study was granted by the UNSW Australia Human Research Ethics Committee, and all other relevant institutional review boards. Written informed consent was obtained from participating individuals. All study procedures were developed in accordance with the revised 1975 Helsinki Declaration. 


\section{Results}

The total number of participants recruited to AHOD by March 2013 was 3894. This analysis included six-monthly data transfers to end March 2013 for the 20 (74 \%) AHOD sites which reported Indigenous status. Study participants were 2197 of 2613 (84.1\%) individuals enrolled at these 20 sites for whom Indigenous status was available. There were $42(1.9 \%)$ Indigenous participants in our study population.

Demographic and clinical data at the time of enrolment to AHOD are summarised in Table 1. Characteristics at enrolment were similar for participants with missing Indigenous status and those for whom Indigenous status was reported (data not shown). However, a higher proportion $(8.9 \%)$ of those with missing Indigenous status reported both male homosexual contact and injecting drug use (IDU) as potential HIV risk factors, more participants with missing Indigenous status were ARV-naive at enrolment (41.1\%), and more of those without Indigenous status recorded were missing a CD4 count and HIV viral load measurement at enrolment ( $29.1 \%$ \& $33.9 \%$, respectively).

At enrolment, the median age of Indigenous participants was younger than non-Indigenous participants (37 years, IQR 32-46 years vs. 41 years, IQR 35-49 years; $p=0.061$ ) but median time since HIV diagnosis was similar (5.0 years, IQR 1.7-9.3 years vs 6.5 years, IQR 2.7-11.8 years; $p=$ 0.136). Mean CD4 counts were also similar between Indigenous and non-Indigenous participants at enrolment to AHOD $\left(530 / \mathrm{mm}^{3}\left(\mathrm{SD} \quad 306 / \mathrm{mm}^{3}\right) \& 522 / \mathrm{mm}^{3}(\mathrm{SD} \quad 278 /\right.$ $\mathrm{mm}^{3}$; respectively; $p=0.858$ ). Compared with nonIndigenous participants, a higher proportion of Indigenous participants were female $(p=0.029)$, living in nonmetropolitan areas $(p<0.001)$, and reported potential HIV exposures of heterosexual contact $(p=0.022)$ and injecting drug use ( $p=0.082)$ (Table 1). In addition, fewer Indigenous participants reported male-to-male sexual contact alone as their most likely HIV risk exposure $(p=0.002$; Table 1). Most participants, irrespective of Indigenous status, had an undetectable HIV viral load, and over $40 \%$ of both groups had a CD4 count of $>500 / \mathrm{mm}^{3}$. Similar proportions of Indigenous and non-Indigenous participants were currently infected with hepatitis B (HBsAg positive: $2.4 \%$ vs $3.9 \%$ respectively; $p=$ 0.575 ) or had evidence of current or past hepatitis C infection (HCV antibody positive: $16.7 \%$ vs $10.7 \%$ respectively; $p=0.215$ ). There was little difference at enrolment between Indigenous and non-Indigenous participants in total cholesterol (median $4.7 \mathrm{mmol} / \mathrm{L}$ vs. $5.0 \mathrm{mmol} / \mathrm{L}$, respectively, $p=0.679$ ), HDL (median $1.3 \mathrm{mmol} / \mathrm{L}$ vs. $1.1 \mathrm{mmol} / \mathrm{L}$, respectively, $p=0.382$ ), triglycerides (median $1.6 \mathrm{mmol} / \mathrm{L}$ vs. $1.7 \mathrm{mmol} / \mathrm{L}$, respectively, $p=0.620$ ), and blood glucose (median $4.7 \mathrm{mmol} / \mathrm{L}$ vs $5.1 \mathrm{mmol} / \mathrm{L}$, respectively, $p=0.195$ ) measurements.
Follow-up amongst Indigenous and non-Indigenous participants was $332 \& 16270$ person-years, respectively. Patient data were available for only 17 (40.5\%) Indigenous and 882 (40.9\%) non-Indigenous participants at the time of commencing their first cART regimen. At initiation of therapy, mean CD4 count $\left(360 / \mathrm{mm}^{3}\right.$ vs $\left.430 / \mathrm{mm}^{3}, p=0.301\right)$ and proportion starting cART at a CD4 count $<200 / \mathrm{mm}^{3}$ ( $26.7 \%$ vs $17.2 \%, p=0.335)$ were similar between Indigenous and non-Indigenous participants, respectively. At the time of cART initiation, few Indigenous $(4.2 \%)$ and nonIndigenous $(8.8 \%)$ participants had suffered a prior AIDSdefining illness $(p=0.715)$. There was no significant difference between Indigenous and non-Indigenous participants in 1st-line cART regimen prescribed $(p=0.879)$ with most Indigenous $(58.3 \%)$ and non-Indigenous $(53.1 \%)$ participants being prescribed a non-nucleoside reverse transcriptase inhibitor (NNRTI)-containing regimen.

HIV viral load measurements were available at 12 and 24 months after cART initiation for $20(47.6 \%)$ and 21 (50.0\%) Indigenous participants and 950 (44.1\%) and 1005 (44.6 \%) non-Indigenous participants. Virological suppression (defined as HIV viral load $<400$ copies/ml) was achieved in similar proportions of Indigenous and non-Indigenous participants at 12 months post-cART initiation $(60.0 \%$ vs $71.4 \%, p=0.841)$ and at 24 months post-cART initiation ( $81.0 \%$ vs $76.5 \%, p=0.635)$.

Indigenous status was not independently associated with shorter time to change from 1st -line to 2nd-line cART regimen $(p=0.957)$ when controlling for factors associated with more rapid change from 1st -line cART regimen (Table 2).

The rate of laboratory tests during follow-up by Indigenous status are outlined in Table 3. Indigenous participants were tested significantly less often for HIV markers (CD4 count and HIV viral load), while testing rates of lipids and blood glucose among Indigenous participants were almost half that of non-Indigenous participants.

The rate of death among Indigenous participants during the study period was $0.3 / 100$ person-years $(95 \% \mathrm{CI}$ 0.07-16.78) compared with $0.93 / 100$ person-years (95\% CI 0.79-2.00) among non-Indigenous participants (logrank $p=0.232$ ). There was only one death among Indigenous participants which was attributed to a non-HIVrelated condition, while non-HIV causes of death accounted for approximately two-thirds $(n=97,63.8 \%)$ of deaths in non-Indigenous participants.

Loss to follow-up (LTFU) during the study period (defined as no clinic visit for $\geq 12$ months) was similar in both groups, occurring among 8 (19.1 \%) Indigenous participants (rate 2.41/100 person-years, $95 \%$ CI 1.04-4.75) and 493 (22.9 \%) of non-Indigenous participants (rate 3.03/100 person-years, $95 \%$ CI 2.77-3.31) (logrank $p=0.531)$. 
Table 1 Baseline patient characteristics by indigenous status at enrolment to the Australian HIV observational database

\begin{tabular}{|c|c|c|c|c|c|c|}
\hline & \multirow{2}{*}{\multicolumn{2}{|c|}{$\frac{\text { Non-indigenous }}{(n=2155)}$}} & \multirow{2}{*}{\multicolumn{2}{|c|}{$\frac{\text { Indigenous }}{(n=42)}$}} & \multirow{2}{*}{\multicolumn{2}{|c|}{$\frac{\text { Total }}{(N=2197)}$}} \\
\hline & & & & & & \\
\hline & $n$ & $\%$ & $n$ & $\%$ & $n$ & $\%$ \\
\hline \multicolumn{7}{|l|}{ Gender } \\
\hline Female & 100 & 4.6 & 5 & 11.9 & 105 & 4.8 \\
\hline Male & 2051 & 95.2 & 36 & 85.7 & 2087 & 95.0 \\
\hline Transgender & 4 & 0.2 & 1 & 2.4 & 5 & 0.2 \\
\hline \multicolumn{7}{|l|}{$\begin{array}{l}\text { Reported HIV exposure } \\
\text { category }\end{array}$} \\
\hline Blood products & 10 & 0.5 & 0 & 0.00 & 10 & 0.5 \\
\hline Heterosexual & 170 & 7.9 & 8 & 19.1 & 178 & 8.1 \\
\hline IDU & 51 & 2.4 & 3 & 7.1 & 54 & 2.5 \\
\hline MSM & 1812 & 84.1 & 28 & 66.7 & 1840 & 83.8 \\
\hline MSM \& IDU & 60 & 2.8 & 1 & 2.4 & 61 & 2.8 \\
\hline Other & 24 & 1.1 & 1 & 2.4 & 25 & 1.1 \\
\hline missing & 28 & 1.3 & 1 & 2.4 & 29 & 1.3 \\
\hline \multicolumn{7}{|l|}{$\begin{array}{l}\text { Prior AIDS-defining } \\
\text { condition }\end{array}$} \\
\hline No & 1777 & 82.5 & 38 & 90.5 & 1815 & 82.6 \\
\hline Yes & 378 & 17.5 & 4 & 9.5 & 382 & 17.4 \\
\hline \multicolumn{7}{|l|}{$\begin{array}{l}\text { Geographical location of } \\
\text { enrolling clinic }\end{array}$} \\
\hline Metropolitan & 1777 & 82.5 & 21 & 50.0 & 1798 & 81.8 \\
\hline Non-metropolitan & 378 & 17.5 & 21 & 50.0 & 399 & 19.2 \\
\hline \multicolumn{7}{|l|}{$\begin{array}{l}\text { Antiretroviral therapy at } \\
\text { enrolment }\end{array}$} \\
\hline Naïve & 562 & 26.1 & 14 & 33.3 & 576 & 26.2 \\
\hline Prior, not current, therapy & 395 & 18.3 & 2 & 4.8 & 397 & 18.1 \\
\hline Current mono/dual therapy & 76 & 3.5 & 1 & 2.4 & 77 & 3.5 \\
\hline $3+\| I,+/-N R T I,+/-N N R T I,+/-P I$ & 16 & 0.7 & 0 & 0.0 & 100 & 4.6 \\
\hline $3+\mathrm{NNRTI}+\mathrm{Pl},+/-\mathrm{NRTI}$, No II & 96 & 4.5 & 1 & 2.4 & 485 & 22.1 \\
\hline 3+ NRTI + NNRTI, No PI, No II & 545 & 25.3 & 13 & 31.0 & 562 & 25.6 \\
\hline 3+ NRTI + PI, No NNRTI, No II & 426 & 19.8 & 7 & 16.7 & 433 & 19.7 \\
\hline 3+ NRTI, No PI, No NNRTI, No II & 39 & 1.8 & 4 & 9.5 & 43 & 2.0 \\
\hline \multicolumn{7}{|l|}{$\begin{array}{l}\text { CD4 count at enrolment } \\
\text { (cells per } \mathrm{mm}^{3} \text { ) }\end{array}$} \\
\hline$<200$ & 199 & 9.2 & 3 & 7.1 & 202 & 9.2 \\
\hline $200-299$ & 214 & 9.9 & 6 & 14.3 & 220 & 10.0 \\
\hline $300-499$ & 650 & 30.2 & 13 & 31.0 & 663 & 30.2 \\
\hline $500+$ & 989 & 45.9 & 18 & 42.9 & 1007 & 45.8 \\
\hline Missing & 103 & 4.8 & 2 & 4.8 & 105 & 4.8 \\
\hline \multicolumn{7}{|l|}{$\begin{array}{l}\text { HIV viral load at enrolment } \\
(\text { copies } / \mathrm{ml}))\end{array}$} \\
\hline$\leq 400$ & 1245 & 57.8 & 25 & 59.5 & 1270 & 57.8 \\
\hline $401-10,000$ & 339 & 15.7 & 5 & 11.9 & 344 & 15.7 \\
\hline$>10,000$ & 470 & 21.8 & 10 & 23.8 & 480 & 21.8 \\
\hline Missing & 101 & 4.7 & 2 & 4.8 & 103 & 4.7 \\
\hline
\end{tabular}


Table 2 Multivariate Cox regression analyses for time to change from first- to second- line combination antiretroviral therapy (CART)

\begin{tabular}{|c|c|c|c|c|c|c|c|}
\hline & n (\%) changed & Time at risk (PY) & Rate of change/100PY & $\mathrm{AHR}$ & $95 \% \mathrm{Cl}$ & $p$-value & Overall $p$ \\
\hline Indigenous & & & & & & & 0.957 \\
\hline No & $416(37.1)$ & 4946.7 & 14.2 & 1 & - & - & \\
\hline Yes & $6(25.0)$ & 112.6 & 16.0 & 1.01 & $0.63-1.63$ & 0.957 & \\
\hline Year of HIV diagnosis & & & & & & & 0.662 \\
\hline$<1997$ & $148(27.9)$ & 2429.9 & 15.8 & 1 & - & - & \\
\hline$\geq 1997$ & $240(46.5)$ & 2229.0 & 12.4 & 0.96 & $0.80-1.15$ & 0.662 & \\
\hline Missing & $34(35.0)$ & 400.4 & 15.7 & 1.15 & $0.88-1.52$ & 0.300 & \\
\hline Year of starting CART & & & & & & & $<0.001$ \\
\hline Prior to 2000 & $104(18.5)$ & 2634.5 & 17.4 & 1 & - & - & \\
\hline 2000 or later & $318(54.6)$ & 2424.8 & 10.9 & 0.54 & $0.46-0.63$ & $<0.001$ & \\
\hline Clinic setting & & & & & & & $<0.001^{\#}$ \\
\hline General practice & $157(44.5)$ & 1965.9 & 10.0 & 1 & - & - & \\
\hline Hospital outpatient & $92(36.8)$ & 958.1 & 16.5 & 1.36 & $1.10-1.69$ & 0.005 & \\
\hline Sexual Health Clinic & $173(32.0)$ & 2135.3 & 17.2 & 1.53 & $1.28-1.83$ & $<0.001$ & \\
\hline $\begin{array}{l}\text { Prior mono or dual } \\
\text { antiretroviral therapy }\end{array}$ & & & & & & & 0.081 \\
\hline No & $354(41.1)$ & 4012.5 & 12.6 & 1 & 1 & - & \\
\hline Yes & $68(24.0)$ & 1046.8 & 20.5 & 1.24 & $0.97-1.59$ & 0.081 & \\
\hline Hepatitis C antibody positive & & & & & & & 0.053 \\
\hline No & $389(37.9)$ & 4600.7 & 13.9 & 1 & - & - & \\
\hline Yes & $33(28.0)$ & 458.6 & 18.5 & 1.25 & $1.00-1.58$ & 0.053 & \\
\hline Prior AIDS-defining illness & & & & & & & 0.304 \\
\hline No & $391(37.4)$ & 4711.4 & 13.9 & 1 & & & \\
\hline Yes & $31(31.3)$ & 348.0 & 19.5 & 1.16 & $0.88-1.52$ & 0.304 & \\
\hline $\begin{array}{l}\text { CD4 count at time of } \\
\text { commencing CART (per } \mathrm{mm}^{3} \text { ) }\end{array}$ & & & & & & & $0.011^{*}$ \\
\hline$<200$ & $45(32.1)$ & 531.0 & 17.9 & 1 & - & - & \\
\hline 200-349 & $82(43.9)$ & 808.4 & 13.0 & 0.85 & $0.64-1.13$ & 0.267 & \\
\hline$>350$ & $215(44.7)$ & 2404.0 & 11.1 & 0.73 & $0.57-0.93$ & 0.010 & \\
\hline missing & $80(23.8)$ & 1315.8 & 19.5 & 0.96 & $0.76-1.22$ & 0.746 & \\
\hline $\begin{array}{l}\text { HIV viral load at time of } \\
\text { commencing cART (copies } / \mathrm{ml} \text { ) }\end{array}$ & & & & & & & $0.200^{*}$ \\
\hline$\leq 400$ & $150(49.3)$ & 1439.0 & 10.7 & 1 & - & - & \\
\hline $400-10000$ & $124(41.1)$ & 1426.6 & 12.5 & 1.09 & $0.87-1.36$ & 0.436 & \\
\hline$>10000$ & $70(34.0)$ & 897.2 & 15.2 & 1.17 & $0.92-1.48$ & 0.200 & \\
\hline missing & $78(23.5)$ & 1296.5 & 19.6 & 1.22 & $0.60-2.49$ & 0.582 & \\
\hline First-line CART regimen & & & & & & & $<0.001^{\#}$ \\
\hline PI-containing (no NNRTI or II) & $104(23.8)$ & 1535.4 & 21.7 & 1 & - & - & \\
\hline NNRTI-containing (No PI or II) & $290(47.6)$ & 3185.3 & 10.0 & 0.56 & $0.47-0.65$ & $<0.001$ & \\
\hline Other $( \pm N N R T I \pm P I \pm I I)$ & $28(28.6)$ & 338.6 & 20.7 & 1.01 & $0.78-1.32$ & 0.927 & \\
\hline
\end{tabular}

Indigenous status included a priori in multivariate model; change defined as addition of $\geq 2$ new drugs or $\geq 1$ new class in regimen, off treatment periods were included in duration of time to change; missing categories not included in calculations of $p$-values. Factors not associated on univariate analysis ( $p>0.1$ ) with shorter time to change from 1st to 2nd line cART were: gender, age at 1st cART, sexual orientation and past/current Hepatitis B infection

PY Person-years, AHR Adjusted hazard ratio, Cl Confidence interval, $C A R T$ combination antiretroviral therapy (at least 3 antiretroviral agents used in combination), PI protease inhibitor, NNRTI Non-nucleoside reverse transcriptase inhibitor, I/ Integrase inhibitor

* $p$ for trend, ${ }^{*} p$ for heterogeneity 
Table 3 Rate of laboratory tests during follow-up by Indigenous status

\begin{tabular}{llll}
\hline & Non-Indigenous $^{\mathrm{a}}$ & Indigenous $^{\mathrm{b}}$ & $p$-value \\
\hline Variable & Rate/year $(95 \% \mathrm{Cl})$ & Rate/year $(95 \% \mathrm{Cl})$ & \\
Cholesterol & $0.71(0.70-0.72)$ & $0.43(0.37-0.51)$ & $<0.001$ \\
HDL & $0.53(0.52-0.55)$ & $0.23(0.18-0.29)$ & $<0.001$ \\
Triglycerides & $0.71(0.70-0.72)$ & $0.43(0.37-0.51)$ & $<0.001$ \\
Glucose & $0.71(0.70-0.73)$ & $0.43(0.37-0.51)$ & $<0.001$ \\
CD4 count & $2.97(2.95-3.00)$ & $2.76(2.58-2.94)$ & 0.025 \\
HIV viral load & $2.93(2.90-2.96)$ & $2.53(2.36-2.71)$ & $<0.001$
\end{tabular}

${ }^{a}$ non-Indigenous time at risk: 16270 person-years; ${ }^{b}$ Indigenous time at risk: 332 person-years

\section{Discussion}

As far as we are aware, this is the first study comparing a broad range of HIV clinical outcomes between Indigenous with non-Indigenous Australians. Adverse clinical outcomes appeared no more common among Indigenous participants, although laboratory monitoring of HIV immunological and virological markers, as well as fasting blood glucose and lipids occurred significantly less often among Indigenous participants.

Although numbers of Indigenous participants were relatively small, limiting ability for comparison between groups, the 42 Indigenous participants in fact represent over $10 \%$ of the total number of Indigenous Australians who have ever been diagnosed with $\operatorname{HIV}[1,11]$. As has been the case with Australian national surveillance of HIV [4, 12], within AHOD there has been a lack of uniform and systematic reporting of Indigenous status. Thus, some data on Indigenous status was missing and 7 of the 27 AHOD study sites do not report Indigenous status for any of their participants, potentially limiting generalisability of our findings. Nonetheless, enrolment characteristics among AHOD participants were broadly similar to characteristics of all Indigenous Australians newly diagnosed with HIV in the last decade, including HIV being diagnosed at younger age, a higher proportion of infections attributed to injecting drug use and smaller proportion attributed to MSM contact $[1,13]$.

Virological suppression is currently considered the best measure of successful response to cART. Overall in AHOD more than $80 \%$ of treated participants are virologically suppressed in any calendar year over the last decade [14], which is broadly similar to the rates of suppression with various cART regimens in other settings [15-17]. The 2-year virological suppression rates after commencing cART in our substudy participants of around $80 \%$ irrespective of Indigenous status is encouraging, and is likely to reflect good engagement in care.

The significantly lower rate of testing for immunological, virological and other health parameters among Indigenous participants is of concern. The reasons for less frequent laboratory monitoring of Indigenous participants are unclear as such data are not captured in AHOD. However possible reasons could include economic or geographic challenges in accessing care. If such challenges exist for rural and remote Indigenous people living with HIV, formal programs providing social, financial and travel support to enhance HIV monitoring and care may be beneficial in maintaining their long-term health. Missed follow-up appointments may be another possible reason for less frequent monitoring. Missed appointments for HIV care has been shown to be a strong predictor of subsequent virologic failure among overseas clinic populations [18], including among other populations similarly dispossessed as Australia's Indigenous population [19]. The largest disparity by Indigenous status was observed for frequency of blood glucose and lipid measurements which is perhaps of even greater concern due to the sizeable burden of diabetes and cardiovascular disease among Indigenous Australians [7].

Clinical outcomes appear no worse among Indigenous participants enrolled in AHOD compared with their non-Indigenous counterparts. This may not be representative of the situation among Indigenous patients outside the study. It is likely, at least in part, to reflect engagement in HIV care, as enrolment in AHOD requires attendance at a clinical service providing HIV care. Nonetheless, other health outcomes, such as those among pregnant HIV-positive Indigenous women, have been shown to be equivalent to those among nonIndigenous patients [20], provided that comprehensive, culturally appropriate, multidisciplinary care is provided.

Reasons for LTFU are not collected in AHOD, and could possibly include patients transferring care to another (non-AHOD) clinic or to an AHOD clinic which does not report Indigenous status. We have recently shown higher viral load, longer time under follow-up and prior episodes of LTFU are independent predictors of LFTU in AHOD, although there was no association of LTFU with death [21]. Of note, loss to follow-up among participants in this AHOD substudy, irrespective of Indigenous status, was slightly lower than that among the entire AHOD cohort over the past 15 years (4.04/100PY, 95 $\%$ CI 3.73-4.36) [22]. This suggests better engagement with HIV care among participants enrolled at sites reporting Indigenous status, and again may limit generalisablity of our findings to the wider Indigenous HIV-positive population. Adherence is known to be one of the most important predictors of successful virological suppression among HIV-positive individuals [23] which we were unable to assess in this substudy as very few AHOD sites report adherence to cART. Poor adherence can select for drug resistance and can shorten the regimen's durability [24]. Nonetheless, we examined time to change from 1st to 2nd line therapy as a proxy for adherence and/or 
tolerability of the initial cART regimen and this was no different by Indigenous status. A further limitation was missing data for a large proportion of participants at time of commencing their first cART regimen and from the 2 years following cART commencement. These clinical markers were mostly unavailable as a result of participants who were recruited to AHOD some years after starting cART, and often at a different clinical service than that at which they were first prescribed cART.

\section{Conclusion}

Indigenous patients in our large clinical cohort had lower rates of laboratory testing for HIV and lipid/glucose parameters than non-Indigenous participants. Overall, lipid and glucose testing among Indigenous participants occurred at under half the frequency that is recommended in national guidelines [25]. Given the elevated risk of cardiovascular disease in the general Indigenous community, the additional cardiovascular risk factor of chronic HIV infection [26] warrants further focus on modifiable risk factors to maximise life expectancy in this population.

\section{Competing interests}

All authors declare that they have no competing interests.

\begin{abstract}
Authors' contributions
DJT: Chair of AHOD steering committee, conceived of and led the substudy, interpretation of data, drafted the manuscript; SW: member of AHOD steering committee, acquisition of data, assisted with interpretation of data, revised manuscript for intellectual content; HMcM: member of AHOD steering committee, acquisition of data, assisted with interpretation of data, revised manuscript for intellectual content; CL: member of AHOD steering committee, assisted with interpretation of data, revised manuscript for intellectual content; DBR: Assisted with interpretation of data, revised manuscript for intellectual content; ML: AHOD Senior Coordinator, member of AHOD steering committee, acquisition of data, assisted with interpretation of data, revised manuscript for intellectual content; KP: AHOD Senior Coordinator, member of AHOD steering committee, acquisition of data, performed the statistical analysis, assisted with interpretation of the data and drafting of the manuscript. All authors read and approved the final manuscript.
\end{abstract}

\section{Funding}

The Australian HIV Observational Database is funded as part of the Asia Pacific HIV Observational Database, a program of The Foundation for AIDS Research, amfAR, and is supported in part by a grant from the U.S. National Institutes of Health's National Institute of Allergy and Infectious Diseases (NIAID) (Grant No. U01-Al069907) and by unconditional grants from Merck Sharp \& Dohme; Gilead Sciences; Bristol-Myers Squibb; Boehringer Ingelheim; Janssen-Cilag; ViiV Healthcare. The Kirby Institute is funded by the Australian Government Department of Health and Ageing, and is affiliated with the Faculty of Medicine, UNSW Australia. The views expressed in this publication do not necessarily represent the position of the Australian Government. Australian HIV Observational Database contributors

Asterisks indicate steering committee members in 2014.

New South Wales: D Ellis, Coffs Central Medical Practice, Coffs Harbour; M Bloch, S Agrawal, T Vincent, Holdsworth House Medical Practice, Darlinghurst; D Allen, Holden Street Clinic, Gosford; D Smith, K Allardice, Lismore Sexual Health \& AIDS Services, Lismore; D Baker*, E Odgers, East Sydney Doctors, Surry Hills; DJ Templeton*, CC O'Connor, S Phan, RPA Sexual Health, Camperdown; E Jackson, K McCallum, Blue Mountains Sexual Health and HIV Clinic, Katoomba; M Grotowski, N Ryder, S Taylor, Tamworth Sexual Health Service, Tamworth; D Cooper, A Carr, F Lee, K McRae, K Hesse, St Vincent's
Hospital, Darlinghurst; R Finlayson, S Gupta, Taylor Square Private Clinic, Darlinghurst; R Varma, J Shakeshaft, Nepean Sexual Health and HIV Clinic, Penrith; K Brown, V McGrath, S Halligan, N Arvela Illawarra Sexual Health Service, Warrawong; L Wray, C Thng, R Foster, H Lu, Sydney Sexual Health Centre, Sydney; D Couldwell, Parramatta Sexual Health Clinic; DE Smith*, V Furner, T Errington Albion Street Centre; Clinic 16 - Royal North Shore Hospital, S Fernando; Dubbo Sexual Health Centre, Dubbo; J Watson*, National Association of People living with HIV/AIDS; C Lawrence*, National Aboriginal Community Controlled Health Organisation; B Mulhall*, Department of Public Health and Community Medicine, University of Sydney; M Law*, K Petoumenos*, S Wright*, H McManus*, C Bendall*, M Boyd*, The Kirby Institute, University of NSW. Northern Territory: M Gunathilake, R Payne, Communicable Disease Centre, Royal Darwin Hospital, Darwin. Queensland: M O'Sullivan, S White, Gold Coast Sexual Health Clinic, Miami; D Russell, J Joslin, C Cashman, Cairns Sexual Health Service, Cairns; D Sowden, K Taing, K McGill, Clinic 87, Sunshine Coast-Wide Bay Health Service District, Nambour; D Orth, D Youds, Gladstone Road Medical Centre, Highgate Hill; M Kelly, D Rowling, N Latch, E Warzywoda, Sexual Health and HIV Service in Metro North, Brisbane; B Dickson*, CaraData. South Australia: W Donohue, O'Brien Street General Practice, Adelaide. Victoria: R Moore, S Edwards, S Boyd, Northside Clinic, North Fitzroy; NJ Roth*, H Lau, Prahran Market Clinic, South Yarra; T Read, J Silvers*, W Zeng, Melbourne Sexual Health Centre, Melbourne; J Hoy*, K Watson*, M Bryant, S Price, The Alfred Hospital, Melbourne; I Woolley, M Giles*, T Korman, J Williams*, Monash Medical Centre, Clayton. Western Australia: D Nolan, G Guelfi, Department of Clinical Immunology, Royal Perth Hospital, Perth. New Zealand: G Mills, C Wharry, Waikato District Hospital Hamilton; N Raymond, K Bargh, Wellington Hospital, Wellington. Coding of Death Form (CoDe) reviewers:

D Sowden, J Hoy, L Wray, I Woolley, K Morwood, N Roth, K Choong, CC O'Connor, MA Boyd.

\section{Author details}

${ }^{1}$ The Kirby Institute, UNSW Australia, Sydney, NSW 2052, Australia. ${ }^{2}$ RPA Sexual Health, Sydney Local Health District, Camperdown, NSW 2050, Australia. ${ }^{3}$ Central Clinical School, The University of Sydney, Sydney, NSW 2006, Australia. ${ }^{4}$ The George Institute for Global Health, Level 10, King George V Building, 83-117 Missenden Rd, Camperdown, NSW 2050, Australia. ${ }^{5}$ Cairns Sexual Health Service, PO Box 902, Cairns QLD 4870, Australia. ${ }^{6}$ The University of Melbourne, VIC, Australia. ${ }^{7}$ James Cook University, Queensland, Australia.

Received: 4 March 2015 Accepted: 22 July 2015

Published online: 12 August 2015

\section{References}

1. The Kirby Institute UNSW Australia. Bloodborne viral and sexually transmitted infections in Aboriginal and Torres Strait Islander people: Surveillance and Evaluation Report. 2013. http://kirby.unsw.edu.au/sites/ default/files/hiv/resources/2013ATSIP-ASR.pdf. Accessed 22 May 2015.

2. Ward J, Akre SP, Kaldor JM. Guarding against an HIV epidemic within an Aboriginal community and cultural framework; lessons from NSW. NSW Public Health Bull. 2010;21:78-82.

3. Shea B, Aspin C, Ward J, Archibald C, Dickson N, McDonald A, et al. HIV diagnoses in indigenous peoples: comparison of Australia, Canada and New Zealand. Int Health. 2011;3:193-8.

4. Guthrie JA, Dore GJ, McDonald AM, Kaldor JM. HIV and AIDS in Aboriginal and Torres Strait Islander Australians: 1992-1998. The National HIV Surveillance Committee. Med J Aust. 2000;172:266-9.

5. Lucas GM. Antiretroviral adherence, drug resistance, viral fitness and HIV disease progression: a tangled web is woven. J Antimicrob Chemother. 2005;55:413-6.

6. Bowden F. From strategies to tactics: HIV in Indigenous Australians. Venereology. 1999;12:45-6.

7. ABS \& AlHW. The health and welfare of Australia's Aboriginal and Torres Strait Islander peoples. 2008. http://www.aihw.gov.au/publication-detail/ ?id=6442468085. Accessed 22 May 2015.

8. Kowalska JD, Friis-Moller N, Kirk O, Bannister W, Mocroft A, Sabin C, et al. The Coding Causes of Death in HIV (CoDe) Project: initial results and evaluation of methodology. Epidemiology. 2011;22:516-23.

9. Australian HIV Observational Database. Rates of combination antiretroviral treatment change in Australia, 1997-2000. HIV Med. 2002;3:28-36. 
10. Wright S, Boyd MA, Yunihastuti E, Law M, Sirisanthana T, Hoy J, et al. Rates and factors associated with major modifications to first-line combination antiretroviral therapy: results from the Asia-Pacific region. PLoS One. 2013;8:e64902.

11. Australian Indigenous HealthInfoNet. Summary of HIV/AIDS among Indigenous peoples. 2005. http://www.healthinfonet.ecu.edu.au/ infectious-conditions/hiv-aids/reviews/our-review. Accessed 22 May 2015.

12. Willis J, McDonald K, Saunders M, Grierson J. HIV Futures II: Aboriginal and Torres Strait Islander People Living with HIV. Monograph Series number 30. La Trobe University, Melbourne, Australia: The Australian Research Centre in Sex, Health and Society; 2000.

13. The Kirby Institute UNSW Australia. HIV, viral hepatitis and sexually transmissible infections in Australia, Annual Surveillance Report. 2013. http:// kirby.unsw.edu.au/sites/default/files/hiv/resources/2013AnnualSurvReport.pdf. Accessed 22 May 2015

14. The Kirby Institute UNSW Australia. Australian HIV Observational Database Annual Report. 2014. http://kirby.unsw.edu.au/sites/default/files/hiv/ attachment/AHOD-Report-1Oct-2014.pdf. Accessed 22 May 2015.

15. Hill A, Sawyer W. Effects of nucleoside reverse transcriptase inhibitor backbone on the efficacy of first-line boosted highly active antiretroviral therapy based on protease inhibitors: meta-regression analysis of 12 clinical trials in 5168 patients. HIV Med. 2009;10:527-35.

16. Boffito M, Miralles D, Hill A. Pharmacokinetics, efficacy, and safety of darunavir/ritonavir 800/100 mg once-daily in treatment-naive and -experienced patients. HIV Clin Trials. 2008;9:418-27.

17. Imaz A, Llibre JM, Navarro J, Curto J, Clotet B, Crespo M, et al. Effectiveness of efavirenz compared with ritonavir-boosted protease-inhibitor-based regimens as initial therapy for patients with plasma HIV-1 RNA above 100,000 copies/ml. Antivir Ther. 2014;19:569-77.

18. Buscher A, Mugavero M, Westfall AO, Keruly J, Moore R, Drainoni ML, et al. The association of clinical follow-up intervals in HIV-infected persons with viral suppression on subsequent viral suppression. AIDS Patient Care STDs. 2013;27:459-66.

19. Mugavero MJ, Lin HY, Allison JJ, Giordano TP, Willig JH, Raper JL, et al. Racial disparities in HIV virologic failure: do missed visits matter? J Acquir Immune Defic Syndr. 2009;50:100-8.

20. Gilles MT, Dickinson JE, Cain A, Turner KA, McGuckin R, Loh R, et al. Perinatal HIV transmission and pregnancy outcomes in indigenous women in Western Australia. Aust N Z J Obstet Gynaecol. 2007;47:362-7.

21. McManus H, Petoumenos K, Brown K, Baker D, Russell D, Read T, et al. Loss to follow-up in the Australian HIV Observational Database. Antivir Ther 2014.doi: 10.3851/IMP2916

22. McManus H, O'Connor CC, Boyd M, Broom J, Russell D, Watson K, et al. Long-term survival in HIV positive patients with up to 15 Years of antiretroviral therapy. PLoS One. 2012;7:e48839.

23. Ammassari A, Trotta MP, Shalev N, Marconi P, Antinori A. Beyond virological suppression: the role of adherence in the late HAART era. Antivir Ther. 2012;17:785-92.

24. Parienti JJ, Massari V, Descamps D, Vabret A, Bouvet E, Larouze B, et al. Predictors of virologic failure and resistance in HIV-infected patients treated with nevirapine- or efavirenz-based antiretroviral therapy. Clin Infect Dis. 2004;38:1311-6.

25. Australasian Society for HIV Medicine. Antiretroviral Guidelines 2014. http://arv.ashm.org.au/. Accessed 22 May 2015.

26. Krikke M, van Lelyveld SF, Tesselaar K, Arends JE, Hoepelman IM, Visseren FL. The role of $T$ cells in the development of cardiovascular disease in HIV-infected patients. Atherosclerosis. 2014;237:92-8.

\section{Submit your next manuscript to BioMed Central and take full advantage of:}

- Convenient online submission

- Thorough peer review

- No space constraints or color figure charges

- Immediate publication on acceptance

- Inclusion in PubMed, CAS, Scopus and Google Scholar

- Research which is freely available for redistribution

Submit your manuscript at www.biomedcentral.com/submit 